\title{
An EOQ Model for Deteriorating Items with Power Demand and Time - Varying Holding Cost
}

\author{
Agatamudi Lakshmana Rao ${ }^{1}$, Geremew Muleta ${ }^{2}$ \\ ${ }^{1 \& 2}$ Department of Statistics, College of Natural Sciences, Jimma Uniiversity, Jimma, Ethiopia.
}

\begin{abstract}
In this paper, we consider deterministic inventory model with power demand and constant deteriorating in considered. The time - varying holding cost is al linear function of time. Shortage are allowed and fully backlogged. The items (like food grains, fashion apparels and electronic equipments) have fixed shelflife which decreases with time during the end of the season. Using the differential equations the instantaneous state of inventory is derived. With suitable cost considerations the total cost function is obtained. By minimizing the total cost function the optimal ordering policies are derived. A numerical illustration is presented to demonstrate the model and the sensitivity analysis of various parameters is carried out.
\end{abstract}

Keywords: Constant Deterioration; Power Demand; Inventory; Shortages; Time Dependent Holding Cost

\section{Introduction}

The main objective of the proposed model is to develop an inventory model for a deteriorating item having a time-dependent power demand rate and time-varying holding cost. The literature review of the present paper is discussed as follows:

Deterioration is usually defined as the damage, decay, spoilage, evaporation and obsolescence of item. The process of deterioration is happened in two categories of items. The first category refers to the items that become damaged, spoiled, decayed, loss of utility, evaporative or expired through time like fruits, vegetables, food items, seafood's, agricultural products, flowers, films, cement, fertilizers, oils, gas, medicines and so on, while the other category refers to the items that loss their parts or their total values through time because of the introduction of new technology or the alternatives like fashion and seasonal goods, electronic components, computer chips and mobile phones and so on. For the first category, the items have a short natural life cycle whereas in the second category, the items have a short market life. The literature surveys starting from the first inventory models for deteriorating items by Wihitin (1957) much work has been reported regarding inventory problems dealing with deteriorating items. Raafat (1991), Goel and Giri (2001), Ruxien Li, et al. (2010), Pentico and Drake (2011) have reviewed the inventory models for deteriorating items.

Goswami and Chaudhuri(1991) were first researchers whom studied the inventory model for deteriorating with shortages. Bose, et al. (1995) generalized by Gowswami and Chaudhuri' model and with shortages under inflation and time discounting. Then Wee(1995) concluded in their study that deterministic inventory model for deteriorating items with shortages and declining market. They established the classical EOQ model with constant deterioration rate and with shortages. Moncer Hariga (1996) studied firstly the inventory model on deteriorating items with time - varying demand when shortages are allowed. Some of the recent work in this field has been established by Chang and Ting, (1993), Vinod Kumar, et al. (2011), Mishra et al. (2013). Chang and Dye (1999) established an inventory model with time varying demand and partial backlogging. On the basis on demand variations, Giri et al. (1996a) developed an inventory model for deteriorating items time varying demand and costs. Nirmal Kumar Dauri and Tripati Chakraporti (2014) studied single warehouse system with price dependent demand and shortages. Shukla et al. (2013) also studied an inventory model for deteriorating items with exponential demand rate and shortages. Datta and Pal (1988), Singh and Sehgal (2011), Srichandan Mishra et al. (2012) also studied on inventory model on deteriorating items with various pattern of power demand. Usually, inventory holding cost and demand rate are considered to be constant. But sometimes in reality, we may observe that inventory holding cost and demand rate for physical goods may be time dependent. This paper examines an inventory model with linearly varying holding cost. The objective function is to minimize the total cost of an inventory system based on inventory holding cost, ordering cost and deterioration cost. In reality, the demand rate and the inventory holding cost for physical goods may be time dependent. As time is an important factor in the inventory system, we consider that demand rate and inventory holding cost are time dependent. We have developed an EOQ inventory model for deteriorating items with power demand when the deterioration rate follows a constant rate with time dependent linear holding cost and shortages are allowed.

In this paper, an effort has been made to analyze an EOQ model for deteriorating items by considering the time dependent power demand rate and time dependent linear inventory holding cost. Shortages are allowed and fully backlogged. The proposed model is based on the inventory items like fashion and seasonal goods, 
electronic equipments, computer chips and mobile phones and so on, as they experience fluctuations in the demand rate. The mathematical model has been derived under power demand rate. Through numerical illustration the sensitivity analysis is carried.

\subsection{Notations}

\section{Notations And Assumptions}

The following notations have been used in developing the model

i. $\mathrm{A}_{0}$ : Ordering cost.

ii. $\mathrm{Q}_{0:}$ Initial ordering quantity.

iii. Q: Ordering quantity.

iv. $I(t)$ : The inventory at time $t, 0 \leq t \leq T$.

v. $\lambda(t)$ : The power demand rate, where $\lambda(t)=\frac{d t^{\frac{1}{n}-1}}{n T^{\frac{1}{n}}}$, where $\mathrm{d}$ is the total demand, $\mathrm{n}$ is the pattern of index $(0<\mathrm{n}<\infty)$.

vi. $\theta(\mathrm{t})$ : The constant deteriorating rate of an item, where $\theta(\mathrm{t})=\theta(0<\theta<1)$.

vii. $\mathrm{C}_{1}(\mathrm{t})$ : The time - varying holding cost per unit, where $\mathrm{C}_{1}(\mathrm{t})=\mathrm{a}+\mathrm{b} t, \mathrm{a}, \mathrm{b}>0$.

viii. $C_{d}$ : The cost of each deteriorated unit.

ix. $\mathrm{C}_{2}$ : Shortage cost per unit time.

$\mathrm{x} . \quad \mathrm{T}$ : The length of ordering cycle.

\subsection{Assumptions}

The following assumptions are made in developing the model

i. The inventory system considered as multi items.

ii. The demand rate is deterministic and is power demand function of time.

iii. The deterioration rate is considered as constant.

iv. Lead time is zero.

v. Shortages are allowed and fully backlogged.

\section{Mathematical Formulation of The Model}

Let $\mathrm{Q}$ be the total amount of inventory produced or purchased at the beginning of each period and after fulfilling backorders let us assume we get an amount $\mathrm{Q}_{0}$ as initial inventory. Let $\mathrm{d}$ be the total demand during period $\mathrm{T}$. Inventory level gradually decreases during the period $\left(0, \mathrm{t}_{1}\right)$ due to market demand and deterioration of items and reaches to zero at time $t=t_{1}$. Shortages occur during time period $\left(t_{1}, T\right)$ which is fully backlogged. Let $I(t)$ be the on hand inventory at any time t. The differential equations which the on hand inventory $I(t)$ must satisfy to different parts of the cycle time $\mathrm{T}$ are the following

$$
\begin{aligned}
& \frac{d}{d t} I(t)+\theta(t) I(t)=-\lambda(t), 0 \leq t \leq t_{1} \\
& \frac{d}{d t} I(t)=-\lambda(t), t_{1} \leq t \leq T
\end{aligned}
$$

where $\theta(\mathrm{t})=\theta$ and $\lambda(t)=\frac{d t^{\frac{1}{n}-1}}{n T^{\frac{1}{n}}}$, with the initial conditions, $\mathrm{I}\left(\mathrm{t}_{1}\right)=\mathrm{Q}_{0}$ and $\mathrm{I}\left(\mathrm{t}_{1}\right)=0$.

Substituting $\lambda(t)$ in equations (1) and (2) and solving the differential equations and neglecting higher order terms of $\theta$, the on hand inventory at time ' $t$ ' is obtained as

$$
\begin{aligned}
& I(t)=Q_{0} e^{-\theta t}-\frac{d}{T^{1 / n}} e^{-\theta t}\left[t^{1 / n}+\frac{\theta}{n+1} t^{\frac{1}{n}+1}\right], \quad 0 \leq t \leq t_{1} \\
& I(t)=\frac{d}{T^{1 / n}}\left[t_{1}^{1 / n}-t^{1 / n}\right], t_{1} \leq t \leq T
\end{aligned}
$$

Thus, the initial order quantity is obtained by putting the boundary condition $I\left(t_{1}\right)=0$ in equation (3).

Therefore,

$Q_{0}=\frac{d}{T^{1 / n}}\left[t_{1}{ }^{1 / n}+\frac{\theta}{n+1} t_{1}^{\frac{1}{n}+1}\right]$

The ordering quantity $\mathrm{Q}$ is obtained from the equation $Q=Q_{0}+d-\frac{d t_{1}^{1 / n}}{T^{1 / n}}$

Therefore,

$Q=d\left[\frac{1}{T^{1 / n}}\left(\frac{\theta}{n+1} t_{1}^{\frac{1}{n}+1}\right)+1\right]$

The total demand during the cycle period $\left[0, \mathrm{t}_{1}\right]$ is 
$\int_{0}^{t_{1}} \lambda(t) d t=\int_{0}^{t_{1}} \frac{d t^{\frac{1}{n}-1}}{n T^{\frac{1}{n}}} d t=d\left(\frac{t_{1}}{T}\right)^{1 / n}$

The number of deteriorated units is

$Q_{0}-\int_{0}^{t_{1}} \lambda(t) d t=\frac{d}{T^{1 / n}}\left[\frac{\theta}{n+1} t_{1}^{\frac{1}{n}+1}\right]$

The deterioration cost $(\mathrm{DC})$ for the cycle $\left[0, \mathrm{t}_{1}\right]=\mathrm{C}_{\mathrm{d}}$ (the number of deteriorated units)

$C_{d} \frac{d}{T^{1 / n}}\left[\frac{\theta}{n+1} t_{1^{\frac{1}{n}+1}}\right]$

The total in inventory holding cost (IHC) for the cycle $\left[0, t_{1}\right]$ is

$\int_{0}^{t_{1}} C_{1}(t) I(t) d t=\int_{0}^{t_{1}}(a+b t)\left[Q_{0} e^{-\theta t}-\frac{d}{T^{1 / n}} e^{-\theta t}\left[t^{1 / n}+\frac{\theta}{n+1} t^{\frac{1}{n}+1}\right]\right] d t$

Substituting the value of $\mathrm{Q}_{0}$ from (5), the total inventory holding cost (8), we obtain

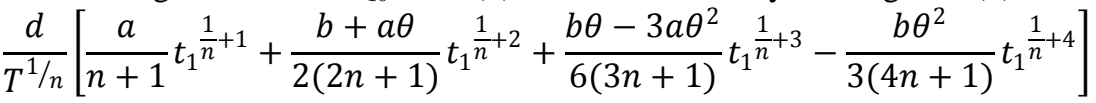

The shortage cost for the cycle $\left(\mathrm{t}_{1}, \mathrm{~T}\right)$ is

$\int_{t_{1}}^{T}-I(t) C_{2} d t=-C_{2} \int_{t_{1}}^{T} \frac{d}{T^{1 / n}}\left[t_{1}{ }^{1 / n}-t^{1 / n}\right] d t$

On simplification

$\frac{-C_{2} d}{T^{1 / n}}\left[t_{1}{ }^{1 / n}\left(T-t_{1}\right)+\frac{n}{n+1}\left(t_{1^{\frac{1}{n}+1}}-T^{\frac{1}{n}+1}\right)\right]$

Let $\mathrm{K}\left(\mathrm{t}_{1}, \mathrm{~T}\right)$ be total cost per unit time. Since the total cost is the sum of ordering cost $(\mathrm{OC})$, deteriorating cost (DC), inventory holding cost (IHC) and shortage cost (SC), the total cost per unit time becomes

$$
\begin{aligned}
K\left(t_{1}, T\right) & =\frac{A_{0}}{T}+\frac{C_{d} d \theta}{T^{\frac{1}{n}+1}(n+1)} t_{1}^{\frac{1}{n}+1} \\
& +\frac{d}{T^{\frac{1}{n}+1}}\left[\frac{a}{n+1} t_{1}^{\frac{1}{n}+1}+\frac{b+a \theta}{2(2 n+1)} t_{1}{ }^{\frac{1}{n}+2}+\frac{b \theta-3 a \theta^{2}}{6(3 n+1)} t_{1} \frac{1}{n}+3-\frac{b \theta^{2}}{3(4 n+1)} t_{1}^{\frac{1}{n}+4}\right] \\
& -\frac{C_{2} d}{T^{\frac{1}{n}+1}}\left[t_{1}{ }^{1 / n}\left(T-t_{1}\right)+\frac{n}{n+1}\left(t_{1}{ }^{\frac{1}{n}+1}-T^{\frac{1}{n}+1}\right)\right]
\end{aligned}
$$

\section{Optimal Pricing And Ordering Policies of The Model}

In this section we obtain the optimal policies of the inventory system under study. To find the optimal values of $\mathrm{t}_{1}$ and $\mathrm{T}$, we obtain the first order partial derivatives of $K\left(t_{1}, T\right)$ given in equation (11) with respect to $\mathrm{t}_{1}$ and $\mathrm{T}$ and equate them to zero. The condition for minimization of $K\left(t_{1}, T\right)$ is

$$
D=\left|\begin{array}{ll}
\frac{\partial^{2} K\left(t_{1}, t_{3}\right)}{\partial t_{1}^{2}} & \frac{\partial^{2} K\left(t_{1}, t_{3}\right)}{\partial t_{1} \partial t_{3}} \\
\frac{\partial^{2} K\left(t_{1}, t_{3}\right)}{\partial t_{1} \partial t_{3}} & \frac{\partial^{2} K\left(t_{1}, t_{3}\right)}{\partial t_{3}{ }^{2}}
\end{array}\right|>0
$$

Differentiating $K\left(t_{1}, T\right)$ given in equation (11) with respect to $t_{1}$ and equating to zero, one can get

$$
\left(C_{d} \theta+\frac{a}{n}\right) t_{1}^{1 / n}+\frac{b+a \theta}{2 n} t_{1}^{\frac{1}{n}+1}+\frac{b \theta-3 a \theta^{2}}{6 n} t_{1}^{\frac{1}{n}+2}-\frac{b \theta^{2}}{3 n} t_{1}^{\frac{1}{n}+3}-C_{2}\left(\frac{T}{n} t_{1}^{\frac{1}{n}-1}-\frac{1}{n} t_{1}^{\frac{1}{n}}\right)=0
$$

Differentiating $K\left(t_{1}, T\right)$ given in equation (11) with respect to $\mathrm{T}$ and equating to zero, one can get

$$
\begin{aligned}
& \frac{A_{0}}{T^{2}}+\frac{C_{d} \theta d}{n T^{-\left(\frac{1}{n}+2\right)}} t_{1}^{\frac{1}{n}+1}+\frac{d(n+1)}{n T^{-\left(\frac{1}{n}+2\right)}}\left[\frac{a}{n+1} t_{1}^{\frac{1}{n}+1}+\frac{b+a \theta}{2(2 n+1)} t_{1}^{\frac{1}{n}+2}+\frac{b \theta-3 a \theta^{2}}{6(3 n+1)} t_{1}^{\frac{1}{n}+3}-\frac{b \theta^{2}}{3(4 n+1)} t_{1}^{\frac{1}{n}+4}\right] \\
& +C_{2} d\left[\frac{n+1}{n T^{-\left(\frac{1}{n}+2\right)}} t_{1}-\frac{1}{n T^{-\left(\frac{1}{n}+1\right)}} t_{1}^{\frac{1}{n}}-T^{\frac{1}{n}}\right]=0
\end{aligned}
$$

Solving equations (12) and (13) simultaneously, we obtain the optimal times $t_{1}{ }^{*}$ of $t_{1}$ and $\mathrm{T}^{*}$ of $\mathrm{T}$ are obtained. The optimum ordering quantity $\mathrm{Q}^{*}$ of $\mathrm{Q}$ in the cycle of length $\mathrm{T}$ is obtained by substituting the optimal values of $\mathrm{t}_{1}{ }^{*}, \mathrm{~T}^{*}$ in equation (6) 


\section{Numerical Illustrations}

In this section we discuss the solution procedure of the model through a numerical illustration by obtaining the optimal times, optimum ordering quantity and the total cost of an inventory system. For the numerical illustrations of the model, the values of various parameters in proper units can be taken as follows:

$\mathrm{A}_{0}=500, \mathrm{C}_{\mathrm{d}}=2, \mathrm{C}_{2}=4, \mathrm{a}=12, \mathrm{~b}=10, \theta=0.4, \mathrm{n}=2$ and $\mathrm{d}=50$

Substituting these values the optimal times, optimal ordering quantity and total cost are computed and presented in Table 1.

From Table1 it is observed that the cost parameters, deteriorating parameters and demand parameters have a tremendous influence on the optimal values of times, ordering quantity and total cost.

Table 1: Optimal values of $\mathrm{t}_{1}{ }^{*}, \mathrm{~T}^{*}, \mathrm{Q}^{*}$ and $\mathrm{K}^{*}$ for different values of parameters

\begin{tabular}{|c|c|c|c|c|c|c|c|c|c|c|c|}
\hline $\mathbf{A}_{0}$ & $\mathbf{C}_{\mathrm{d}}$ & $\mathrm{C}_{2}$ & $\mathbf{a}$ & b & $\square$ & $\mathbf{n}$ & d & $t_{1}$ & $\mathbf{T}$ & $\mathbf{Q}$ & $\mathbf{K}$ \\
\hline 500 & 2 & 4 & 12 & 10 & 0.4 & 2 & 50 & 1.453 & 7.657 & 54.219 & 142.422 \\
\hline 525 & & & & & & & & 1.396 & 7.794 & 53.940 & 144.189 \\
\hline 550 & & & & & & & & 1.351 & 7.941 & 53.715 & 145.988 \\
\hline \multirow{22}{*}{575} & & & & & & & & 1.305 & 8.096 & 53.491 & 147.768 \\
\hline & 2.1 & & & & & & & 1.455 & 7.647 & 54.232 & 142.587 \\
\hline & 2.2 & & & & & & & 1.457 & 7.636 & 54.244 & 142.751 \\
\hline & 2.3 & & & & & & & 1.460 & 7.626 & 54.257 & 142.916 \\
\hline & & 4.2 & & & & & & 1.426 & 7.891 & 54.040 & 142.972 \\
\hline & & 4.4 & & & & & & 1.412 & 8.175 & 53.913 & 143.578 \\
\hline & & 4.6 & & & & & & 1.400 & 8.520 & 53.784 & 144.189 \\
\hline & & & 12.6 & & & & & 1.474 & 7.535 & 54.346 & 144.635 \\
\hline & & & 13.2 & & & & & 1.493 & 7.429 & 54.464 & 146.842 \\
\hline & & & 13.8 & & & & & 1.512 & 7.336 & 54.574 & 149.044 \\
\hline & & & & 10.5 & & & & 1.470 & 7.581 & 54.315 & 143.541 \\
\hline & & & & 11.0 & & & & 1.486 & 7.511 & 54.408 & 144.66 \\
\hline & & & & 11.5 & & & & 1.502 & 7.447 & 54.497 & 145.779 \\
\hline & & & & & 0.42 & & & 1.304 & 6.238 & 54.173 & 157.139 \\
\hline & & & & & 0.44 & & & 1.354 & 7.827 & 54.128 & 140.667 \\
\hline & & & & & 0.46 & & & 1.074 & 8.542 & 52.921 & 136.835 \\
\hline & & & & & & 2.1 & & 1.424 & 7.695 & 54.115 & 140.736 \\
\hline & & & & & & 2.2 & & 1.396 & 7.729 & 54.009 & 139.111 \\
\hline & & & & & & 2.3 & & 1.369 & 7.759 & 53.903 & 137.548 \\
\hline & & & & & & & 52.5 & 1.473 & 7.642 & 57.029 & 146.555 \\
\hline & & & & & & & 55.0 & 1.492 & 7.628 & 59.838 & 150.684 \\
\hline & & & & & & & 57.5 & 1.509 & 7.616 & 62.647 & 154.811 \\
\hline
\end{tabular}

\section{Sensitivity Analysis}

We now study the effect of changes in the values of the system parameters $A_{0}, C_{d}, C_{2}, a, b, \theta, n$ and $d$ on the optimal cost and number of reorder. The sensitivity analysis is performed by changing each of the parameters by $-15 \%,-10 \%,-5 \%, 0 \%, 5 \%, 10 \%$ and $15 \%$ taking one parameter at a time and keeping the remaining parameters unchanged. The relationship between the parameters and the optimal values of the schedule is shown in Figure 1.

The analysis is based on the Numerical illustration and the results are shown in the Table 2. The following points are observed.

1) $T^{*}, K^{*}$ increases while $t_{1}{ }^{*}, Q^{*}$ decreases with decrease and increase in value of the parameter $A_{0}$. Here $t_{1}{ }^{*}$, $\mathrm{T}^{*}, \mathrm{Q}^{*}$ and $\mathrm{K}^{*}$ are moderately sensitive to change in $\mathrm{A}_{0}$.

2) $T^{*}, Q^{*}, K^{*}$ increase while $t_{1}^{*}$ decrease with decrease and increase in value of the parameter $C_{d}$. Here $t_{1}{ }^{*}, T^{*}$, $\mathrm{Q}^{*}$ and $\mathrm{K}^{*}$ are low sensitive to change in $\mathrm{C}_{\mathrm{d}}$.

3) $T^{*}, K^{*}$ increases while $t_{1}{ }^{*}, Q^{*}$ decreases with decrease and increase in value of the parameter $C_{2}$. Here $t_{1}{ }^{*}$, $\mathrm{T}^{*}, \mathrm{Q}^{*}$ and $\mathrm{K}^{*}$ are low sensitive to change in $\mathrm{C}_{2}$.

4) $t_{1}{ }^{*}, Q^{*}, K^{*}$ increase while $T^{*}$ decrease with decrease and increase in value of the parameter a. Here $t_{1}{ }^{*}, T^{*}$, $\mathrm{Q}^{*}$ and $\mathrm{K}^{*}$ are moderate sensitive to change in a.

5) $t_{1}{ }^{*}, Q^{*}, K^{*}$ increase while $T^{*}$ decrease with decrease and increase in value of the parameter $b$. Here $t_{1}{ }^{*}, T^{*}$, $\mathrm{Q}^{*}$ and $\mathrm{K}^{*}$ are low sensitive to change in $\mathrm{b}$.

6) $\mathrm{T}^{*}$ increase while $\mathrm{t}_{1}{ }^{*}, \mathrm{Q}^{*}, \mathrm{~K}^{*}$ decreases with decrease and increase in value of the parameter $\theta$. Here $\mathrm{t}_{1}{ }^{*}, \mathrm{~T}^{*}$, $\mathrm{Q}^{*}$ and $\mathrm{K}^{*}$ are high sensitive to change in $\theta$.

7) $T^{*}$ increase while $t_{1}{ }^{*}, Q^{*}, K^{*}$ decreases with decrease and increase in value of the parameter $n$. Here $t_{1}{ }^{*}, T^{*}$, $\mathrm{Q}^{*}$ and $\mathrm{K}^{*}$ are moderately sensitive to change in $\mathrm{n}$.

8) $t_{1}{ }^{*}, Q^{*}, K^{*}$ increase while $T^{*}$ decrease with decrease and increase in value of the parameter $d$. Here $t_{1}{ }^{*}, T^{*}$, $\mathrm{Q}^{*}$ and $\mathrm{K}^{*}$ are high sensitive to change in $\mathrm{d}$. 
An EOQ Model for Deteriorating Items with Power Demand and Time - Varying Holding Cost

Table 2: Sensitivity analysis of the model

\begin{tabular}{|c|c|c|c|c|c|c|c|c|}
\hline \multirow{2}{*}{$\begin{array}{l}\text { Variation } \\
\text { Parameters }\end{array}$} & \multirow{2}{*}{$\begin{array}{l}\text { optimal } \\
\text { policies }\end{array}$} & \multicolumn{7}{|c|}{ Change in parameters } \\
\hline & & $-15 \%$ & $-10 \%$ & $-5 \%$ & $0 \%$ & $5 \%$ & $10 \%$ & $15 \%$ \\
\hline \multirow[t]{4}{*}{$\mathbf{A}_{0}$} & $\mathbf{t}_{1}{ }^{*}$ & 1.576 & 1.536 & 1.495 & 1.453 & 1.396 & 1.351 & 1.305 \\
\hline & $\mathbf{T}^{*}$ & 7.289 & 7.406 & 7.528 & 7.657 & 7.794 & 7.941 & 8.096 \\
\hline & $\mathbf{Q}^{*}$ & 54.884 & 54.662 & 54.44 & 54.219 & 53.94 & 53.715 & 53.491 \\
\hline & $\mathbf{K}^{*}$ & 136.824 & 138.714 & 140.58 & 142.422 & 144.189 & 145.988 & 147.768 \\
\hline \multirow{4}{*}{$\mathbf{C}_{\mathrm{d}}$} & $\mathbf{t}{ }^{*}$ & 1.446 & 1.448 & 1.451 & 1.453 & 1.455 & 1.457 & 1.46 \\
\hline & $\mathbf{T}^{*}$ & 7.69 & 7.679 & 7.668 & 7.657 & 7.647 & 7.636 & 7.626 \\
\hline & $\mathbf{Q}^{*}$ & 54.18 & 54.193 & 54.206 & 54.219 & 54.232 & 54.244 & 54.257 \\
\hline & $\mathbf{K}^{*}$ & 141.928 & 142.093 & 142.257 & 142.422 & 142.587 & 142.751 & 142.916 \\
\hline \multirow[t]{4}{*}{$\mathbf{C}_{2}$} & $\mathbf{t}_{1}{ }^{*}$ & 1.499 & 1.483 & 1.468 & 1.453 & 1.426 & 1.412 & 1.4 \\
\hline & $\mathbf{T}^{*}$ & 7.145 & 7.291 & 7.46 & 7.657 & 7.891 & 8.175 & 8.52 \\
\hline & $\mathbf{Q}^{*}$ & 54.579 & 54.461 & 54.341 & 54.219 & 54.04 & 53.913 & 53.784 \\
\hline & $\mathbf{K}^{*}$ & 140.65 & 141.235 & 141.826 & 142.422 & 142.972 & 143.578 & 144.189 \\
\hline \multirow[t]{4}{*}{$\mathbf{a}$} & $\mathbf{t}_{1}{ }^{*}$ & 1.365 & 1.392 & 1.417 & 1.453 & 1.474 & 1.493 & 1.512 \\
\hline & $\mathbf{T}^{*}$ & 8.181 & 7.974 & 7.801 & 7.657 & 7.535 & 7.429 & 7.336 \\
\hline & $\mathbf{Q}^{*}$ & 53.719 & 53.879 & 54.027 & 54.219 & 54.346 & 54.464 & 54.574 \\
\hline & $\mathbf{K}^{*}$ & 135.692 & 137.926 & 140.152 & 142.422 & 144.635 & 146.842 & 149.044 \\
\hline \multirow[t]{4}{*}{ b } & $\mathbf{t}_{1}{ }^{*}$ & 1.382 & 1.403 & 1.422 & 1.453 & 1.47 & 1.486 & 1.502 \\
\hline & $\mathbf{T}^{*}$ & 7.939 & 7.834 & 7.74 & 7.657 & 7.581 & 7.511 & 7.447 \\
\hline & $\mathbf{Q}^{*}$ & 53.845 & 53.956 & 54.063 & 54.219 & 54.315 & 54.408 & 54.497 \\
\hline & $\mathbf{K}^{*}$ & 139.011 & 140.131 & 141.252 & 142.422 & 143.541 & 144.66 & 145.779 \\
\hline \multirow[t]{4}{*}{$\square$} & $\mathbf{t}_{1}{ }^{*}$ & 1.795 & 1.714 & 1.604 & 1.453 & 1.274 & 1.104 & 1.012 \\
\hline & $\mathbf{T}^{*}$ & 6.681 & 6.871 & 7.166 & 7.657 & 7.827 & 8.238 & 8.542 \\
\hline & $\mathbf{Q}^{*}$ & 55.273 & 55.136 & 54.806 & 54.219 & 54.173 & 54.128 & 52.921 \\
\hline & $\mathbf{K}^{*}$ & 158.689 & 154.248 & 148.808 & 142.422 & 140.667 & 136.835 & 132.835 \\
\hline \multirow[t]{4}{*}{$\mathbf{n}$} & $t_{1}{ }^{*}$ & 1.532 & 1.5 & 1.482 & 1.453 & 1.424 & 1.396 & 1.369 \\
\hline & $\mathbf{T}^{*}$ & 7.511 & 7.564 & 7.616 & 7.657 & 7.695 & 7.729 & 7.759 \\
\hline & $\mathbf{Q}^{*}$ & 54.453 & 54.362 & 54.32 & 54.219 & 54.115 & 54.009 & 53.903 \\
\hline & $\mathbf{K}^{*}$ & 147.776 & 145.92 & 144.169 & 142.422 & 140.736 & 139.111 & 137.548 \\
\hline \multirow[t]{4}{*}{ d } & $\mathbf{t}_{1}{ }^{*}$ & 1.36 & 1.39 & 1.417 & 1.453 & 1.473 & 1.492 & 1.509 \\
\hline & $\mathbf{T}^{*}$ & 7.72 & 7.695 & 7.674 & 7.657 & 7.642 & 7.628 & 7.616 \\
\hline & $\mathbf{Q}^{*}$ & 45.734 & 48.545 & 51.355 & 54.219 & 57.029 & 59.838 & 62.647 \\
\hline & $\mathbf{K}^{*}$ & 129.96 & 134.099 & 138.237 & 142.422 & 146.555 & 150.684 & 154.811 \\
\hline
\end{tabular}

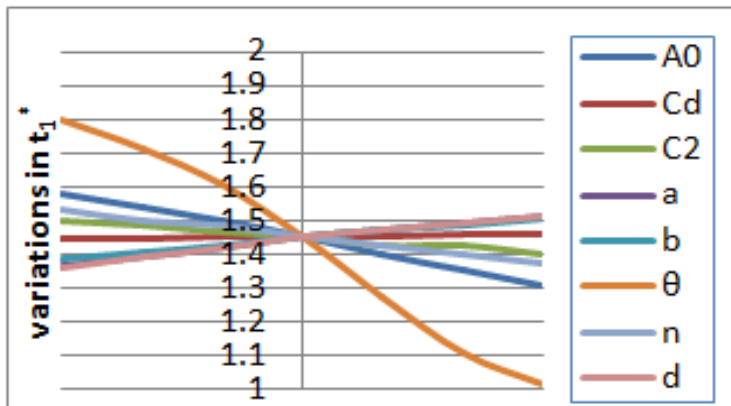

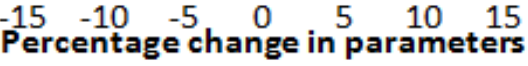

(a)

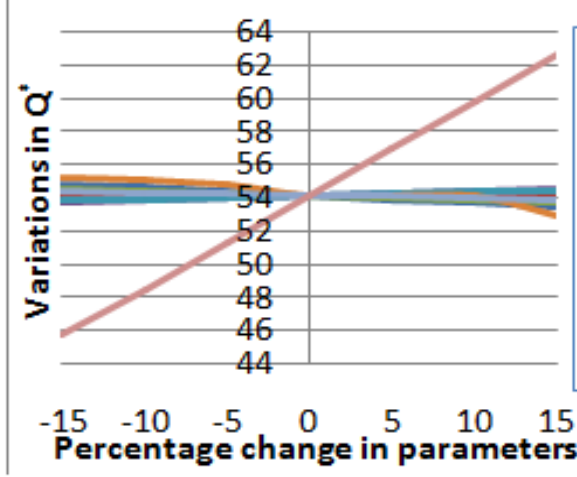

(c)

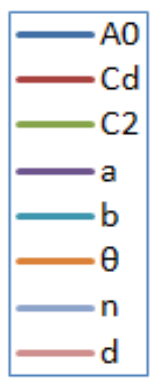

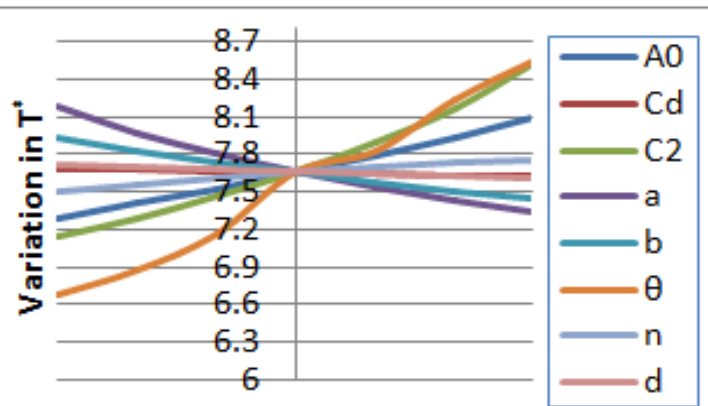

$\begin{array}{lllllll}-15 & -10 & -5 & 0 & 5 & 10 & 15\end{array}$

Percentage change in parameters

(b)

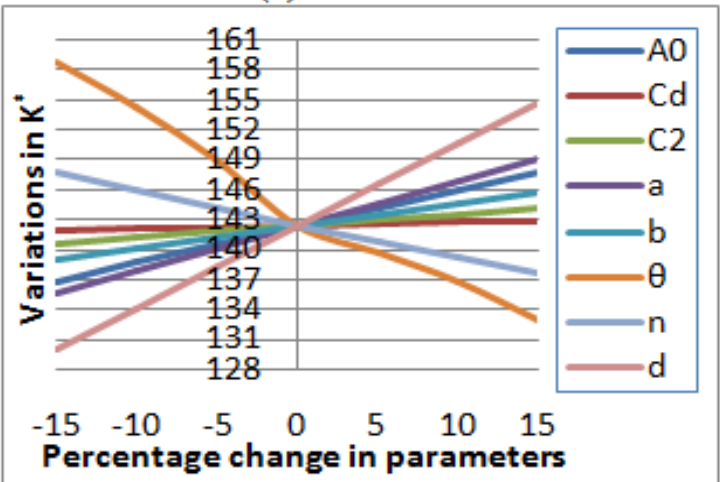

(d)

Fig 1: Relationship between optimal values and parameters 


\section{Conclusions}

In this paper, an inventory model is developed which investigates the optimal order quantity of the on hand inventory due to power demand rate. The items like food grains, fashion apparels and electronic equipments etc., have fixed shelf - life which decreases with time during the end of the season and the storage period in which the demand, deterioration, and holding cost depend upon time. This model is closed analytically by minimizing the total inventory cost. Finally, the model has been verified by the numerical illustration along with sensitivity analysis. In the future study, it is hoped to extended the proposal model into several situations having linear increasing demand, stock dependent, price dependent demand. This model further extended to three - parameter Weibull distribution or Gamma distribution deterioration. Further - more, it may also take practical backlogging into account when determining the optimal replenishment policy.

\section{References}

[1] Bose, S. Goswami, A. and Chaudhuri, K.S. (1995) 'An EOQ model for deteriorating items with linear time - dependent demand rate and shortages under inflation and time discounting', Journal of the Operations Research Society, Vol- 46, pp. 771-782.

[2] Chang, H. J. and Dye, C. Y. (1999) 'An EOQ Model for Deteriorating Items with Time Varying Demand and Partial Backlogging', Journal of the Operational Research Society, Vol. 50, pp. 1176-1182.

[3] http://dx.doi.org/10.1057/palgrave.jors.2600801

[4] Chung, K. J. and Ting, P. S. "A Heuristic for Replenishment for Deteriorating Items with a Linear Trend in Demand," Journal of the Operational Research Society, Vol. 44, pp. 1235-1241.

[5] Datta, T.K. and Pal, A.K. (1988) 'Order level inventory systems with power demand pattern for items with variable rate of deterioration', Indian Journal of Pure and Applied Mathematics, Vol.19 (1), pp. 1043-1053.

[6] Giri, B.C., Goswami, A. and Chaudhuri, K.S. (1996a) 'An EOQ model for deteriorating items with time varying demand and costs', Journal of Operational Research Society, Vol.47, pp. 1398-1405.

[7] Goswami, A. and Chaudhuri, K.S. (1991) 'An EOQ model for deteriorating items with shortages and a linear trend in demand', Journal of the Operational Research Society, Vol.42(12), pp. 1105-1110.

[8] Goyal, S. K. and Giri, B. C. "Recent Trends in Modeling of Deteriorating Inventory," European Journal of Operational Research, Vol. 134(1), pp. 1-16. http://dx.doi.org/10.1016/S0377-2217 (00)00248-4

[9] Li, R. Lan, H. and Mawhinney, J. R. "A Review on Deteriorating Inventory Study," Journal of Service Science and Management, Vol.3 (1), pp.117-129. http://dx.doi.org/10.4236/jssm.2010.31015

[10] Mishra, V. K. Singh, L. S. and Kumar, R. "An Inventory Model for Deteriorating Items with Time-Dependent Demand and TimeVarying Holding Cost under Partial Backlogging," Journal of Industrial Engineering International, Vol. 9(4), pp. 1-5. http://dx.doi.org/10.1186/2251-712X-9-4

[11] Moncer Hariga (1996) 'Optimal EOQ models for deteriorating items with time - varying demand', Journal of Operations Research Society, Vol - 47, $1228-1246$.

[12] Nirmal Kumar Duari and Tripati Chakrabarti (2014) 'An order level EOQ model for deteriorating items in a single wherehouse system with price dependent demand and shortages', American Journal of Engineering Research, Vol - 3, pp. 11-16.

[13] Pentico, D.W. and Drake, M.J. (2011) 'A survey of deterministic models for the EOQ and EPQ with partial backordering', European Journal of Operational Research, Vol.214(2), pp. 179-198.

[14] Raafat, F. "Survey of Literature on Continuously Deteriorating Inventory Model," Journal of the Operational Research Society, Vol. 42(1), pp. 27-37.

[15] Shukala, H.S. Vivek Shukala and Sushil Kumar, Y (2013) 'EOQ model for deteriorating items with exponential demand rate and shortages', Uncertain Supply Chain Management, Vol - 1, pp. 67 - 76.

[16] Singh, S.P. and Sehgal, V.K. (2011) 'An EOQ inventory model for Weibull distributed deteriorating items with power demand pattern and shortages', Journal of Mathematical Sciences, Vol - 1, pp. 99 - 110.

[17] Srichandan Mishra, Raju, L.K. Misra, U.K. and Misra, G. (2012) ' A study of EOQ model with power demand of deteriorating items under the influence of inflation', General Mathematics Notes, Vol - 10, pp. $41-50$

[18] Vinod Kumar Mishra, Lal Sahab Singh and Rakesh Kumar (2013) ' An inventory model for deteriorating items with time dependent demand and time - varying holding cost under partially backlogging', Journal of industrial engineering international, doi: 10.1186/2251-712X-9-4. http://www.jiei-tsb.com/content/9/1/4

[19] Wee, H. M.( 1995) "A deterministic Lot-Size Inventory Model for Deteriorating Items with Shortages and a Declining Market,"Computers and Operations Research, Vol. 22(3), pp. 345-356. http://dx.doi.org/10.1016/0305-0548(94)E0005-R

[20] Whitin, T. M. (1957) "Theory of Inventory Management," Princeton University Press, Princeton, pp. 62-72. 